\title{
11 Spatial Data Infrastructure for Emergency Response in Netherlands
}

\author{
Henk Scholten, Steven Fruijter, Arta Dilo and Erik van Borkulo
}

\begin{abstract}
During the crisis management, several organizations coordinate their emergency work based not only on well-defined policies and procedures (product of careful preparation) but also on the outcomes of the decisionmaking process. Decision-making is a highly complicated process in crisis situations. Good support in decision-making when disaster occurs is of critical importance to react accurately, fast and effectively. Good decisionmaking helps to control damage, save lives and resources, and reduce unwanted consequences of a crisis. Spatial Data Infrastructure (SDI) is increasingly considered a critical aspect of decision-making in disaster management. This paper presents our concept for an appropriate SDI (openstandard generic platform) assisting in administration, analysis of data to predict development of a crisis event and accordingly advise for changes of plans
\end{abstract}

\subsection{Introduction}

The first hours after a disaster happens are very chaotic and difficult but perhaps the most important for successfully fighting the consequences, saving human lives and reducing damages in private and public properties. In these first hours, the good estimation of the current situation is of particular importance. A large number of questions (e.g. where is the emergency situation, how to get there, how many casualties, what kind of information do we have from there), are pending for answering.

Additionally to the unclear situation, many different actors from different sectors (fire brigade, police, paramedics, municipalities, etc.) with, sometimes, contradictory requirements are involved in managing the situation. Since many of the tasks they have to perform are rather different than their daily work routines, a good cooperation and collaboration between different teams is of critical importance. 
There are numerous underlying obstacles that complicate an adequate crisis response (Borkulo et al 2005, Diehl and van der Heide 2005, Kevany 2005, Neuvel et al 2006, Ospina, 2006, Winter et al 2005):

- Lack of good communication between sectors or actors in crisis response. Different sectors operate with particular systems; therefore the exchange of information between all actors in the crisis management becomes difficult.

- Diversity of systems in one sector. It is quite common practice to use various software in different regions or groups of regions. Realising this problem, for example, the Dutch police has already initiated a large project SHERPA aiming at standardisation of the geoinformation provision of all the 25 police regions in the Netherlands.

- A variety of narrow specialised systems for only emergency situations.

- Lack of appropriate platform (user interfaces) for data exchange. The interfaces usually serve tasks and activities of a specific sector (police, fire-fighters, etc.)

- Insufficient standardisation of processes and protocols, especially for data exchange.

- Difficulties in exchange and integration of various data. Resolution, accuracy, updatedness are only few of the challenges.

- Lack of information about the 'information'. Often is unclear where certain information can be found and how reliable it is.

- Management of information from the field (reports, images, video, dynamic data, etc.). Usually this information is stored as unstructured files, which is problematic for systemised analysis, or it is not stored at all.

- Access to existing data is in general very slow.

New systems have to be developed that allow different rescue units to operate together in any critical situation. One of the main challenges is in the spatial domain, i.e. definition of well-defined standardised services for discovery and exchange of information. Such services are closely related also to the development of Spatial Data Infrastructure (SDI) at all levels (local, regional, national and international) for support of disaster management. Initiatives for SDIs are in progress at many levels all over the world, for example INSPIRE in Europe (www.ec-gis.org/inspire). Those have to be further enriched to be able to serve emergency sector. Large international projects, for example, ORCHESTRA (www.eu-orchestra.org), OASIS (www.oasis-fp6.org) and WIN (www.win-eu.org) are already reporting results of their research in this area.

Three aspects of an SDI are especially critical for the success of an emergency response system: generic services that would be available for 
all the actors (on the field and in the commando centre) in a disaster situation; integration of information coming from different sectors, and management of dynamic information; appropriate interfaces for different endusers.

The services developed within this research are context-oriented with respect to the 19 types of disaster as specified in the Netherlands (Diehl and Van der Heide, 2005). User interfaces allow for both request of data and submitting (in-situ) data to the system and are built on systems currently in use in the response sector.

Many kinds of information are needed in crisis response. These are existing data produced by different organisations, and dynamic data collected during a crisis from the different sectors involved in crisis response. Integration of data coming from different sources is an important aspect. Maintenance of dynamic data received from the field is still rather underestimated. Most of the information exchange is currently performed via the telephone.

This paper presents concepts and ideas for the development of an SDI for disaster management. Next section presents the state-of-the-art in the development of SDI. Section 3 discusses the services that are being developed. Section 4 elaborates on graphic user interface used in the moment and demanded by the users. Section 5 concentrates on information management, and a data model for the management of in-situ information. Last section concludes on expected added value of the developments. This research is part of the project 'Geographical Data Infrastructure for Disaster Management' (www.gdi4dm.nl) funded by the Dutch Research and Development Programme 'Space for geo-information'.

\subsection{SDI in emergency response}

SDI has been considered an important aspect of sharing data for years (Abrue et al 2000, Cattenstart and Scholten, 1999, Scholten et al 1999) Currently there are many international (Fabri and Weets 2005) and national initiatives for building SDI (INSPIRE, NEN, etc.). The reports for the EU member states show that a lot of progress is being made towards establishing European SDIs. There has also been progress toward a process of data harmonization as well as to common systems and data models in disaster response and prevention (ORCHESTRA, OASIS, GMES). However, the large number of activities and projects funded by EU shows that the SDI is far from reality. 
From a technical point of view most of the technology that is required for access and exchange of spatial information is available as standards for implementation (e.g. OGC Web Services, SFS, GML), as concepts (e.g. OGC Abstract specifications for open distributed management of geographical imagery) or in process of development. It is worth mentioning that third phase of the OGC Web Services has been completed at the end of last year. Within these phase participants worked on several relevant topics for disaster response such as common architecture, sensor web enablement, Geo-decision support services (GeoDSS), Geo-Digital Right Management (GeoDRM) and Open Location services (OpenLS). Many extensions of existing standards are proposed for further discussions. For example the OGC OpenLS is extended toward indoor tracking (www.opengeospatial.org).

For the communication between the systems in this architecture, the use of web services and XML can be considered the state of the art. On the side of the clients, there is a great diversity ranging from rich clients based on web browsers over classic workstation applications to mainframes with terminals. These clients cover all the use cases for spatial data that so far exist and are based on highly heterogeneous programming and data models.

There are also many contributions from scientific projects. It should be mentioned many approaches for reaching semantic interoperability, search engines based on ontologies, security for agents and web services, as well as processing, indexing and serialization algorithms in the field of computer science. The topic of semantic interoperability is regarded as central and projects with strong industry integration like WIDE8 (IST 200134417) as well as those with a relation to metadata interoperability (like the INVISIP9 project, IST-2000-29640) are in progress.

\subsection{Generic services}

Our major objective within this project is to offer services that solve many of the obstacles that are now faced by emergency response systems. These services aim at improving communication between different actors involved in crises response. The services are part of an infrastructure that integrates and facilitates access to various information, existing data and data coming from the filed. It offers metadata - information about 'the information', exchange of data, etc. The focus is largely on developing contextaware services. 
Defining and implementing an SDI is traditionally done by creating application profiles, where the data model behind the data infrastructure is leading. Generic services based upon open standards can then be developed to make exchange of data possible. The major disadvantage of this approach is that the development of services can be complex and time consuming.

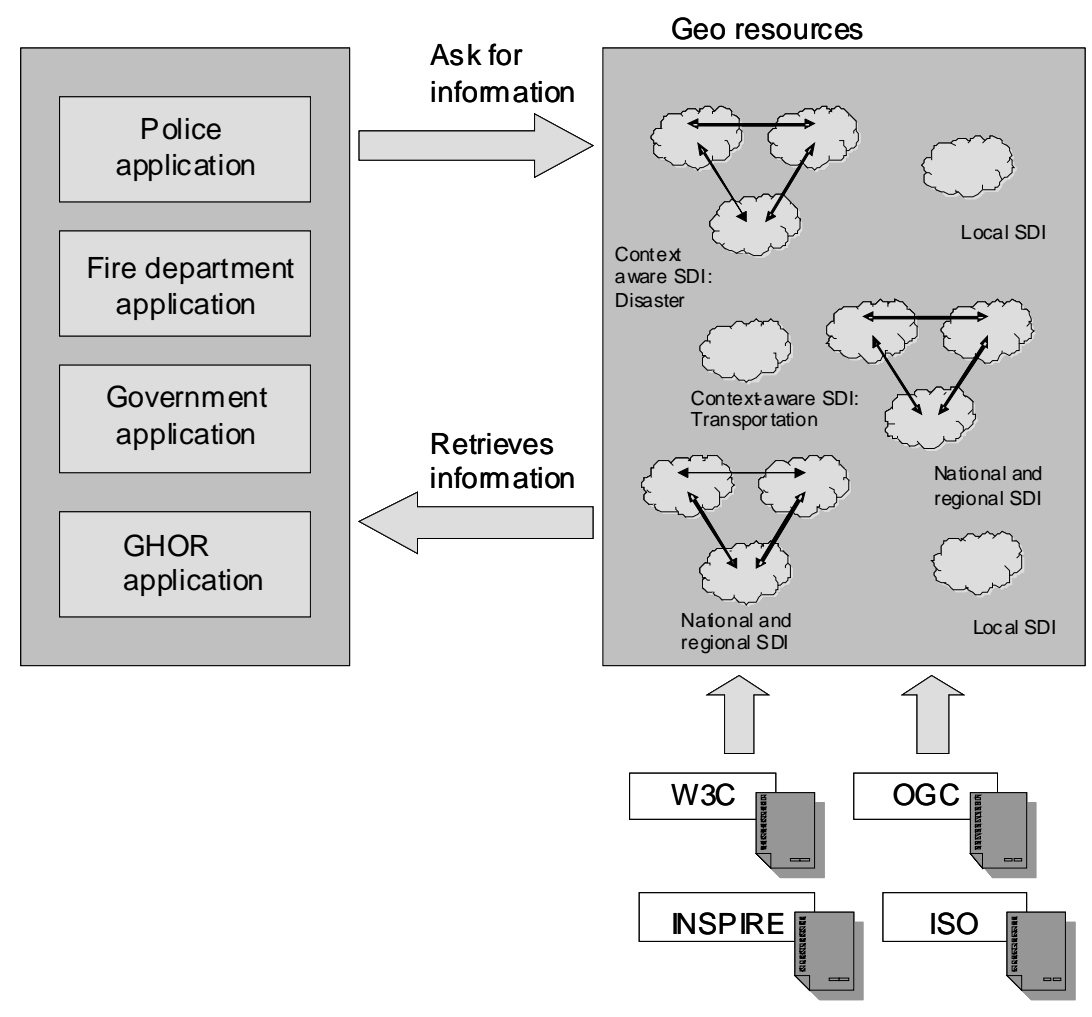

Fig. 1: An overview of context-aware SDI for disaster management.

A different approach is defining and implementing an SDI within the context it is primarily used (Fig. 1). For this project the context is defined with respect to the 19 different disaster types. In this approach, the use scenarios within the current disaster type prevail for the implementation of services within the SDI. Such services only provide access to the data infrastructure that is relevant for the current disaster type. This approach assures to maintain the focus within a certain context, as well as that applica- 
tion designers/architects to be able to use the defined and implemented services within their known specialization.

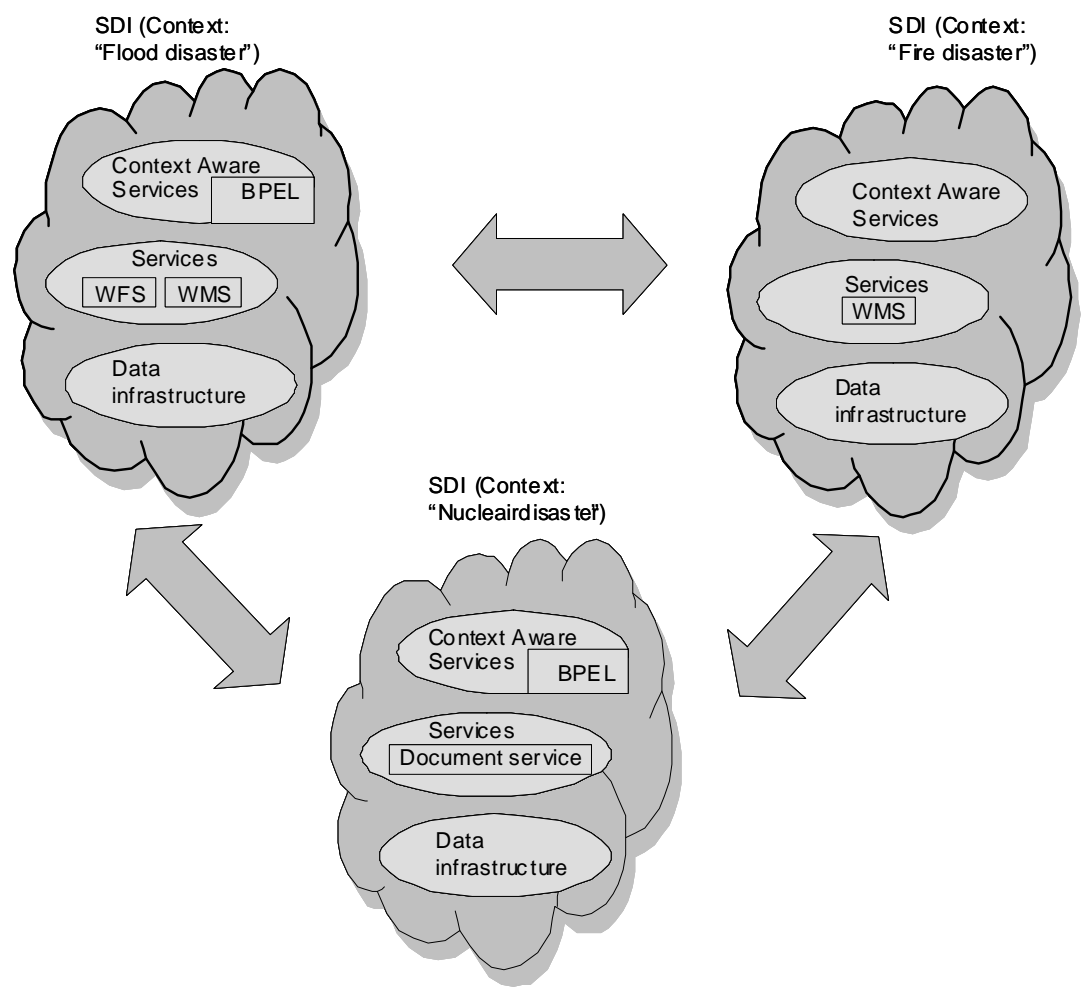

Fig. 2: An example of SDI for the types of disasters: Flood disaster SDI, Fire disaster SDI and Nuclear disaster SDI.

Within data driven (or syntax-aware) SDI's the applications are directly communicating with the services, which make them very dependant and aware of the syntax being used by services or data infrastructures. In context driven SDI's high-level functions within the active context are exposed to the application making the dependency of the underlying services less relevant (Fig. 2:). These functions often consist of a series of calls to various services within the context-aware SDI. This approach is often referred as service chaining. This chain of calls to the various services ismodelled after the workflow designed to be used during emergency situations 


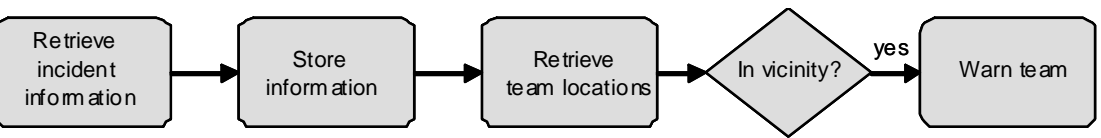

Fig. 3: Workflow of an emergency process.

Fig. 3 shows an example of a workflow during an emergency situation. Information of an incident is retrieved (e.g. by phone or electronically). This information is stored for example by writing it on a paper or whiteboard. In order to warn the appropriate teams, the teams which are in the neighbourhood of the incident are selected and warned if necessary (e.g. by using radiotelephone).

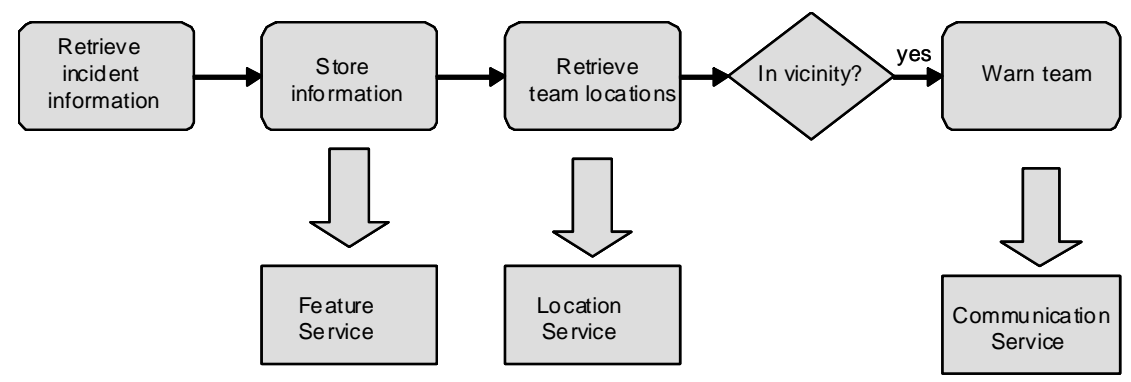

Fig. 4: Workflow of an emergency process implemented using service chaining.

Fig. 4 shows the same example where the actual actions are implemented by a chain of calls to services belonging to the SDI. The Feature Service stores the information in the database described in chapter 5 . The Location Service (e.g. an OpenLS implementation) is responsible for the tracking and tracing of the teams. Finally the Communication Service takes care of sending the information to the teams. Techniques such as BPEL (Business Process Execution Language) are available to model and implement the service chaining. BPEL is an XML based language describing among others the succession of calls to the different services (also called orchestration).

\subsection{Graphic user interface}

The design and development of an appropriate Graphic User Interface (GUI) is yet another challenging task in disaster management. GUI is usually very specific with respect to a particular user, type of device used and functionality to be offered. In disaster management these specifics are even more extreme, due to different user backgrounds, stress, time pressure, fa- 
tigue, etc. Therefore the interface has to be intuitive, easy for use and functional. This project analyses and extends/modifies the GUI of Multiteam ( Fig. 5 and Fig. 6) (www.multiteam.info) and VNet (Fig. 7).

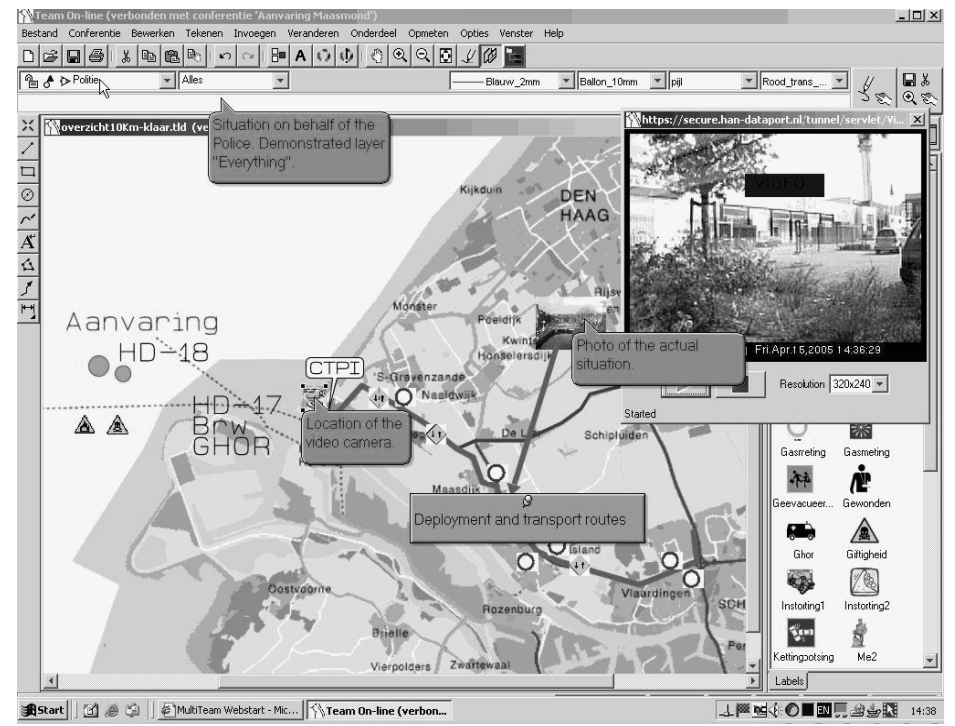

Fig. 5: Graphic user interface of the system Multiteam.

In both systems the different responding agencies in the crisis response (Fire Service, Para medic, Police, municipalities, other special units) can access the system and give the location of their mobile-units (using special symbols) or mark important areas e.g. those not accessible to the Public. The user of the system can send e-mails and request different maps as a background. The systems differ slightly in their functionality and access to the information. While Multiteam has a quite large local database with information, the concept of VNET (Diehl and Van der Heide 2005) is accessing distributed information (stored within the organisations responsible for their own service delivery). In both systems, however, (spatial) analysis is not available yet. The only existing functionalities are map overlay and visual inspection. Simulations (as discussed in flood risk management) are not available at the moment. In addition, compatible communication systems are being developed to improve communication during imminent floods. 


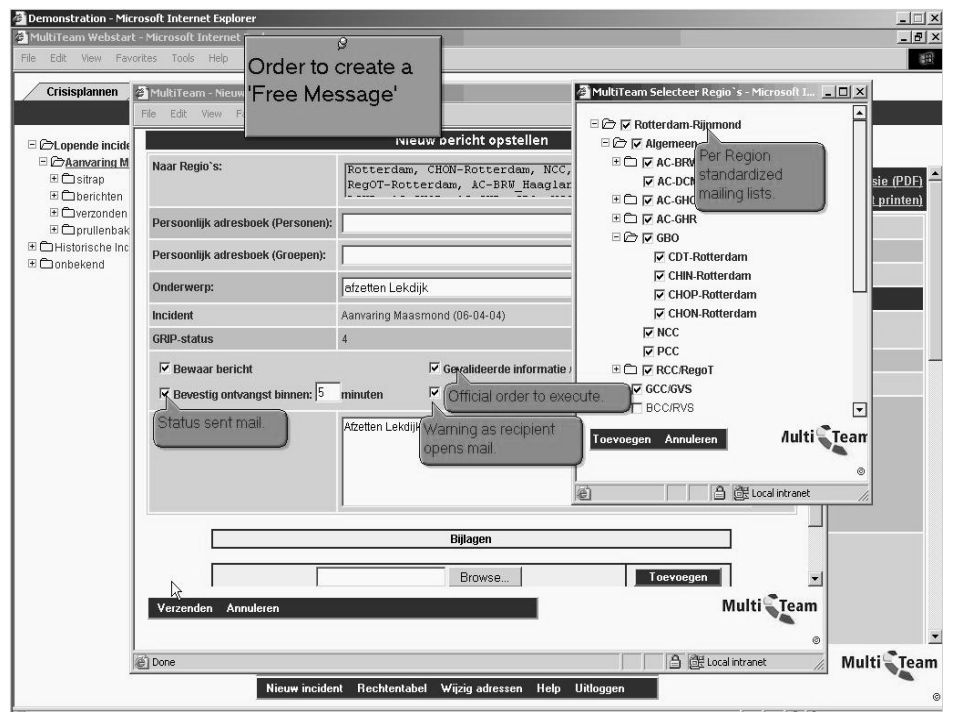

Fig. 6: Interface for e-mail communication.

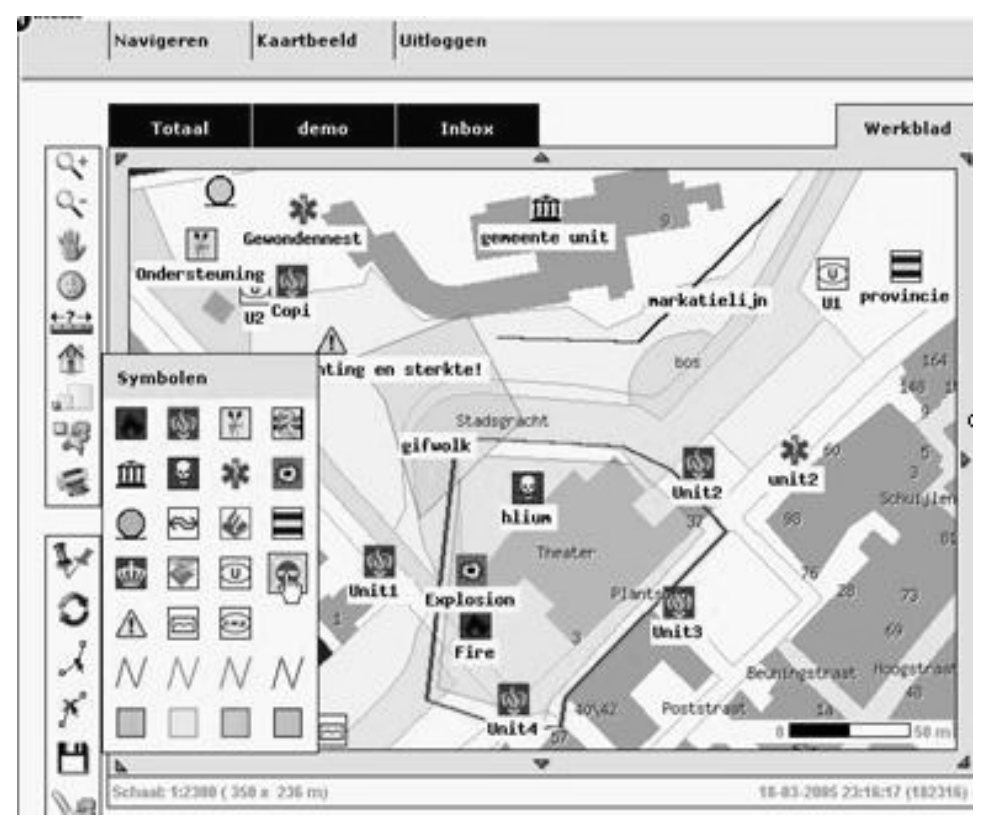

Fig. 7: Graphic user interface of VNet. 
The GUI interface in emergency response should be intuitive, and simple, yet providing the most appropriate information with respect to the user, the used device and the emergency of the situation. Furthermore the access to the data can be dependent on the location of the object, the process, the task and the particular organisation (Capelleveen 2005). It should be also remembered that the behaviour of people changes in critical situations. In this respect, different GUI interfaces is to developed for mobile users and decision-makers in commando centres.

3D display and new visualisation environments are considered as well. Various groups are working already in providing 3D visualisation (Berlo et al 2005, Branco et al 2005, Bodum et al 2005, Kolbe at al 2005, Kwam and Lee 2004). It is well known that 3D visualisation gives a lot of advantages but puts big challenges to the developers of the system. For example, the $3 \mathrm{D}$ visualisation has to be very close to the real view. In contrast to maps, where a lot of symbols are used, 3D view should convey by realism and not by abstraction. Special techniques have to be used to focus attention to the most important information. For example, usage of a textured building amongst shaded ones. 3D models may be represented with plenty of details but in most of the cases this may lead to distraction. In this respect it is very important to keep the balance between important and fortuitous information (Zlatanova and Holweg, 2004).

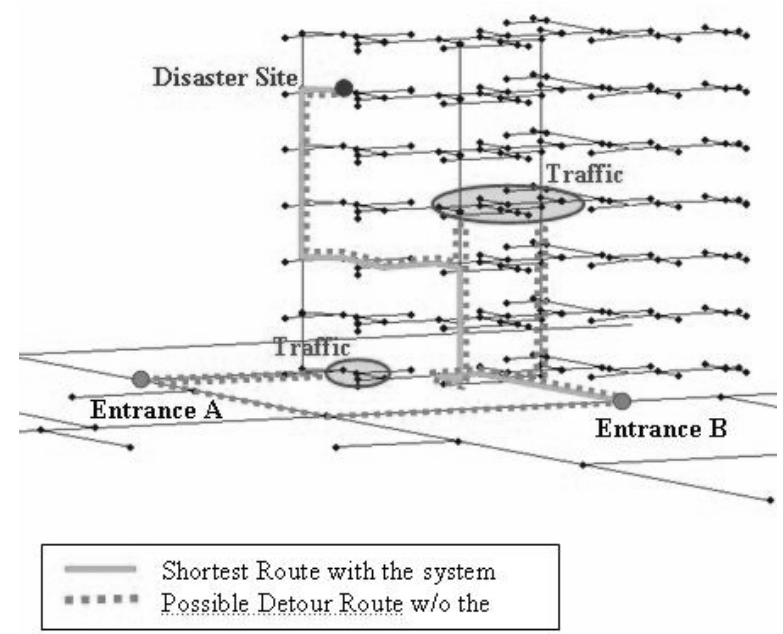

Fig. 8: Navigation routes in a building (from Kwam and Lee, 2004).

3D representations and displays can be critical for indoor routing and navigation (Kwam and Lee 2004, Meijers at al 2005). Considering the 
complexity of modern buildings and the great number of people that can be inside buildings, it is often challenging to organise a quick evacuation. Very often serious problems such as huddle, trample, inaccessibility of exits, etc are observed. Despite all the currently available means (alarm signals, evacuation plans, illuminated signs, etc.), three serious deficiencies are observed (Pu and Zlatanova, 2005): 1) lack of appropriate indoor geoinformation about the structure and the available exits of the building, 2) lack of dynamic information about the current situation and 3) lack of flexible means for evacuation instructions Therefore have investigated possibilities to employ interfaces that dynamically evaluate the possible escape routes. The evacuation routes can be computed using network models (see next section) and the visualization as 3D graphics or appropriate images (Fig. 8) can be transferred to the client application.Very often 3D models are not available, but still a sort of 3D effect can be obtained. (Verbree et al, 2004) have studied the applicability of panoramic images, a CycloMedia (www.cyclomedia.nl) full-colour images or Cyclorama's. The intention of CycloMedia is to cover the Netherlands with cycloramas to support all kinds of geo-information systems and services. All objects and locations are registered systematically from the public roads within cities, districts, etc. The cycloramas are recorded by a very special fisheye lens with a vertical view of 30 degrees below the horizon.

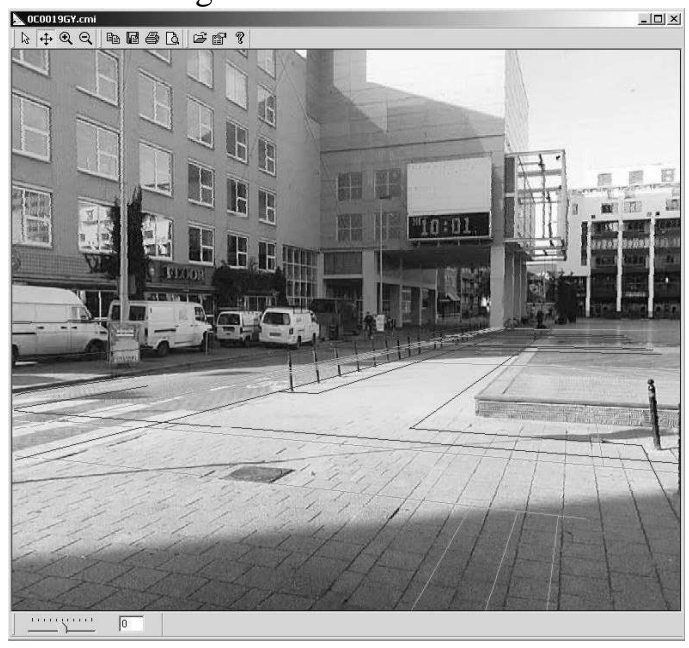

Fig. 9: Cyclorama's, augmented with utility information (from Verbree et al, 2004).

Being geo-referenced, the images can be used for integration with various data. Actually, the cyclorama can function as the 'background layer' to 
display information labels, guiding directions, and position hotspots of other cycloramas in a given neighbourhood. The cycloramas can be integrated in any GIS system, as a clickable object either at the location where the image is taken from or at given addresses. By this, the user gets a far better impression of the surrounding objects and situation. Fig. 9 illustrates a cyclorama image augmented with underground utility information. The cable data are taken from a 2D digital map and transformed in the projection of the image. Such an approach is readily applicable even for the restricted resources (screen, memory, bandwidth, etc.) of mobile devices. The image processing can be performed on a server and the augmented image can be streamed to any type of wireless devices.

This project extensively explores new emerging tangible technologies. Such technologies provide realistic visualization, human-computer interaction, help in situational awareness, and allow for cognitive mapping and collaborative decision making (Scotta et al 2006). Fig 10 illustrates the touch table to be used in the research.

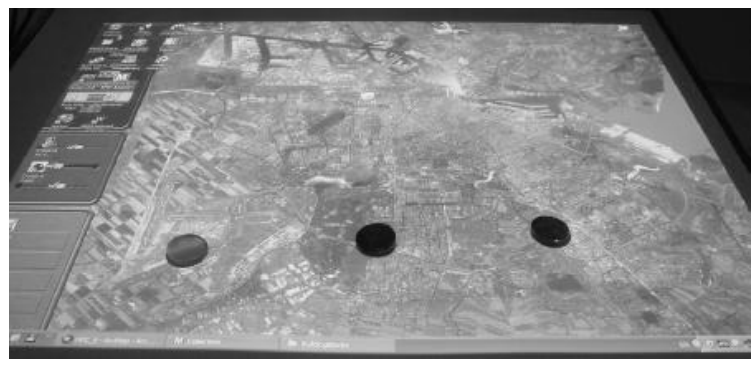

Fig 10: Geodan tangible user interface table (from Scotta et al, 2006).

The Diamond Touch Table is a front projected table. This means that the image is displayed with a beamer hanging above the table. The touch signal is recognized with an array of antennas embedded in the touch surface (www.merl.com). This technique allows not only to determine where the table is touched but also who is touching the table.

\subsection{Management of information}

The information needed during emergency response consists of existing information, e.g. topographic data, network utilities, etc., and information collected at the moment of disaster, the in-situ information. The integration of existing information is done through the use of ontologies (Xu et al. 
2007). In this section we concentrate only on the management of in-situ information, which is an important aspect of the project. This information has to be stored and processed in order to predict the development of a crisis event. The stored information of past crisis events can be further analyzed and used for the prevention phase.

A DBMS system is used for the management of in-situ data, for several important functionality such a system offers: reliable management of large data sets, multi-user control on shared data and crash recovery, automatic locks of single objects while using database transactions for updates, etc. Nowadays several commercial and non-commercial DBMSs offer support for spatial data types: Ingres, Oracle, Informix, IBM DB2, MySQL, PostgreSQL. Some DBMSs (e.g. Oracle Spatial) even support several different spatial models (geometry, topology, network, LRS). The network model is quite appropriate for commutation of evacuation routes combined with 2D/3D visualisation since the geometry of the objects can be stored together with the nodes and links of the graph (Pu and Zlatanova 2005, Meijers et al 2005). These DBMS systems support only 2D spatial data types with their 3D coordinates. Full consideration of the third dimension may require new data types (Zlatanova and Stoter 2006). If needed, 3D topologies (Oosterom et al 2002, Zlatanova et al 2004) at database level and corresponding operations will be investigated. 3D topology may be required to extend the spatial functionality with operations such as 3D routing, and consistent update of data. Some DBMS systems support the temporal aspect, but the spatial and temporal indexing is treated independently. Good spatiotemporal support needs an integrated approach, consisting of proper data types, operations and specific indexing (and clustering) structures (see also Laurini et al, 2005).

A critical question is the selection of the DBMS, as well as the choice between commercial or open source. Important aspects to be considered are the support for different data types, appropriate for handling different kind of information coming during an emergency; support for the temporal component; extendibility with new types and functions. It is expected that information collected during an emergency is of very different nature. Besides various sensor information such as images (terrestrial, aerial), videos, laser-scan (also terrestrial and airborne), large amounts of textual data, audio, etc have to be managed. Most of the information is dynamic; therefore the temporal component is critical. The choice between open source or commercial DBMS is driven from pragmatic reasons. On the one hand, an open source, freeware DBMS (e.g. PostGIS) may have benefits in large area devastating disasters (similar to East Asia Tsunami or the hurricane Katrina) when existing infrastructure is destroyed and a commando centre 
has to be set up in few hours. On the other hand, many organizations in the Netherlands have already commercial DBMS, such as Oracle Spatial.

Oracle Spatial and PostGIS offer the most from the functionality we need. Many units from the emergency sector, e.g. municipalities, have already their data in Oracle. For this reason we have chosen to use Oracle Spatial. We have built a conceptual model for the in-situ data, and have translated it to Oracle Spatial tables, including constraints, indices, validation checks, and new data types. The rest of this section describes a part of the model (Fig. 11), which covers the information used during emergency with dangerous substances (three disaster types).

Fig. 11 shows the tables that store the information, and relationships between the tables. Table Incident stores information about the location of a crisis event, the time it started, its extent, type of the disaster, etc. Two other tables, Sectormal and Gasmal, store information about the possible extent of the incident, calculated from meteorological data. A series of processes is initiated to handle a crisis event. Each process is well defined, and has a specific objective, which determines on which kind of disasters the process will be needed. For example, in case of emergency with dangerous substances, measurements should be performed in the affected area, and the process called 'Observations and Measurements' (Borkulo et al 2005) has to start. The table Process stores information about each process according to the Dutch emergency response procedure: the process type, the incident for which it is initiated, the time the process started and the time it concludes. Table DM_User stores information about personnel of disaster management sectors, and table UserInProcess stores information about which person is involved in which process and the time period of this involvement. Table Measurement stores the result of the 'Observation and Measurements' process. Several measurements may be performed during such a process. The measurement team performs measurements for the checked items, and reports the results in a corresponding form. Table Measurement contains the information from both forms: the specialist form defining the tasks, and the measurement team form giving the results of measurements. The Team table contains information about teams performing measurements. TeamMember table keeps track of persons forming a team, and the period of time they are in the team. The model shown in Fig. 11 does not contain all validity checks and indices; it is though complete in terms of primary key constraints (PK symbol) and foreign key constraints (FK). 


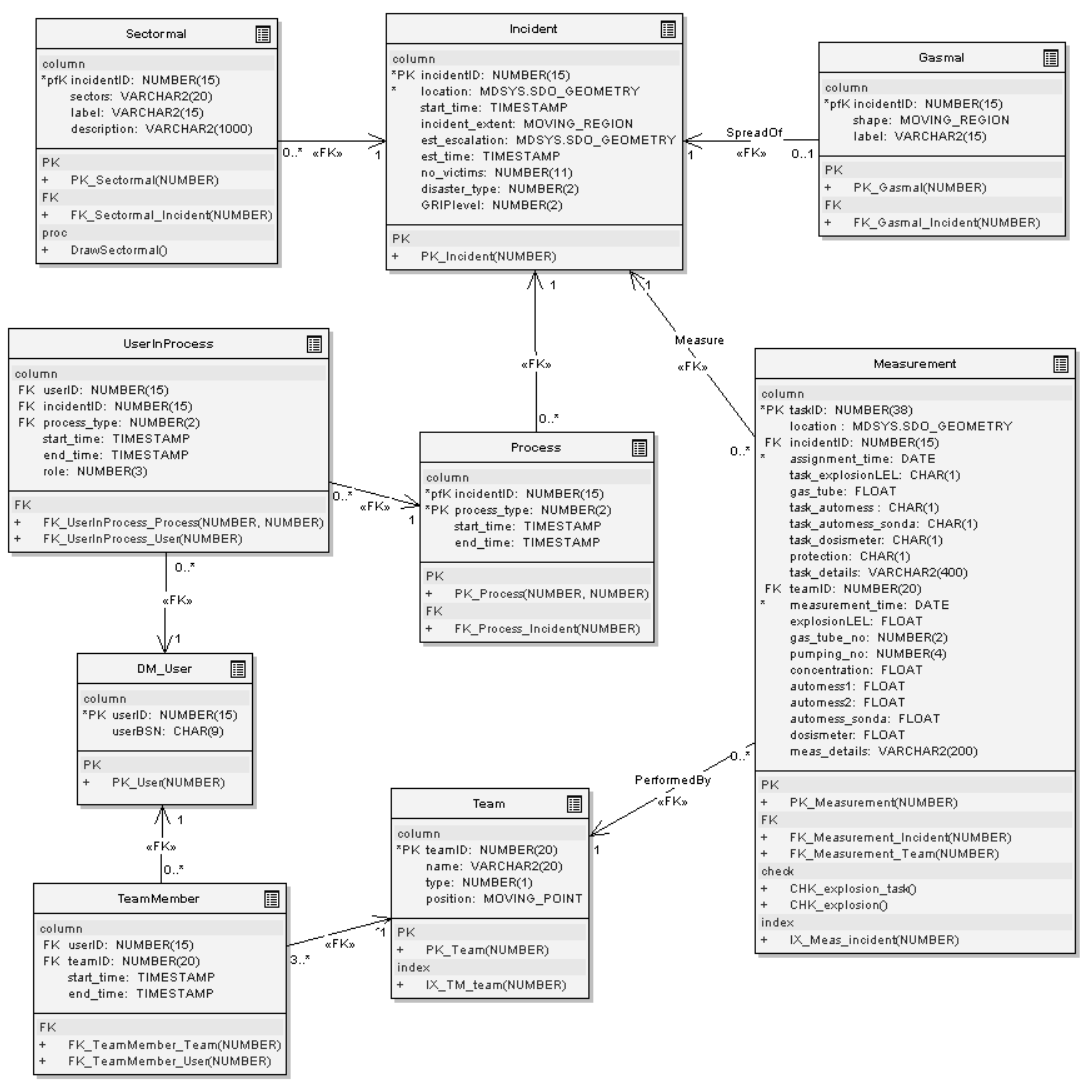

Fig. 11. UML model of Oracle tables holding in-situ information in case of emergency with dangerous substances.

The Oracle Spatial data type MDSYS.SDO_GEOMETRY is used for spatial data, e.g. location of an incident that is a point, or the incident estimated extent that is an area. To store spatiotemporal data we use nested tables of Oracle. An area that changes in time, e.g. the extent of an incident, is stored as a list of pairs (area-shape, time). We have created a new data type MOVING_REGION:

/* Types for a moving region instance, and complete moving region */ CREATE OR REPLACE TYPE MRegionInst AS OBJECT ( meas_time TIMESTAMP,

) ;

region_geo MDSYS.SDO_GEOMETRY

CREATE OR REPLACE TYPE MOVING_REGION AS TABLE OF MRegionInst; / 
Another spatiotemporal type, MOVING_POINT, is created in a similar way. It stores information for a location that changes in time, e.g. the position of a team in the field. These new types are used in the SQL statements for table creation, for example:

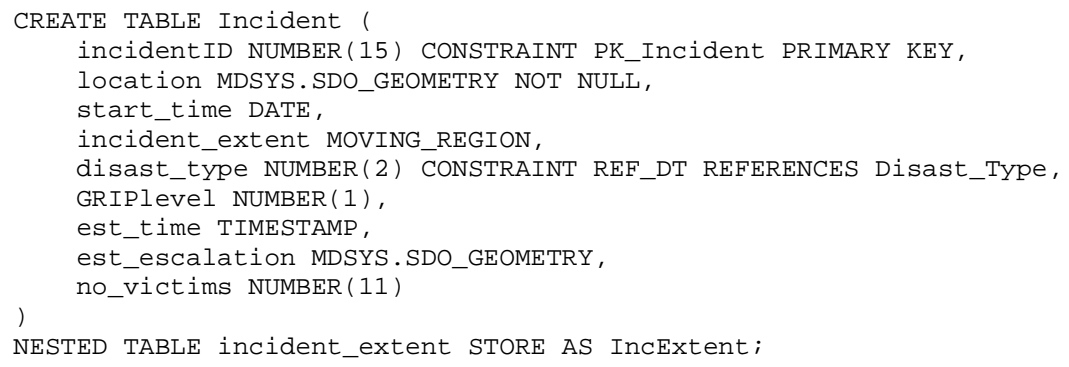

We use Oracle nested tables functionalities to store spatiotemporal data in the tables, and to read these data. The SQL statement below creates a view from the Incident table that transforms spatiotemporal types to simply spatial types (via un-nesting), which can be easily used by services.

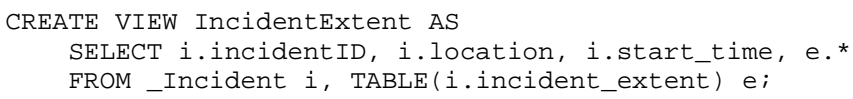

\subsection{Conclusions}

The standardised services developed within this project facilitate the work of emergency sector in a number of directions. We expect that the systems will allow for a better preparation to disaster management, because of the standardised operations able to be exercised in daily work. On the other hand, the temporal data collected from previous disasters can be analysed and used for prevention.

It will be possible a better handling of the first period of an emergency, achieved by providing targeted information rapidly and by collecting relevant information from the field that helps coordinating operations efficiently. This period, called the golden hour, often determines the success of the entire operation, for instance as concerns the ability to save lives.

The integration of command-and-control with field operations can be significantly improved especially the coordination between forces, teams and organisations that participate in emergency management. The nature of the project is such that this impact can be achieved as concerns communication and data management. 
The handling of emergency will also be improved, because information from multiple sources and databases will be possible to access in order to provide the emergency sector with all insights that can be realistically obtained in support of life saving and protection of material assets. This can prevent that vital data will not be usable simply because the data handling technical issues.

The visualisation of requested information will be improved with respect to the specific needs of the users and therefore provided in formats (e.g. images, vector, movies) that are more compatible with the environmental conditions during the emergency.

This 'definitely' will result in a better support to rescuers, based on information provision and coordination, which can on the one hand lead to faster and more effective operations and in the other hand ease the burden of stress on the operations theatre.

However, even 'definitely' needs to be evaluated and proven. As has been stated in the report of the National Research Council (2007) there are a number of factors that will influence the success of a map. Part of the project will be the development of evaluation procedures which will be used during the planned large disaster management exercises. Based on these outcomes we will be able to judge the role of the SDI

\section{References}

Abrue, J., Scholten, H. J., Eijnden, van den B., Gehrels, B. 'Combining Spatial Metadata Search-Engines with Web mapping' in: GIS, Journal for Spatial Information and Decision Making, Vol. 13, October 2000, pp. 8-11.

Berlo, M. van, van Rijk, R. and Buiël, E. A PC-based Virtual Environment for training team decision-making in high-risk situations, in: Proceedings of the 2nd International ISCRAM Conference April 2005, Brussels, Belgium, pp. 195-201.

Bodum, L., Kjems, E., Kolar, J., Ilsøe, P.M. and Overby, J. GRIFINOR: Integrated Object-oriented Solution for navigating real-time 3D virtual environments. in: PJM van Oosterom, S Zlatanova \& EM Fendel (Eds.), Geoinformation for disaster management, Springer Verlag, Heidelberg, pp. 937949.

Borkulo, E van, Scholten, H. J., Zlatanova, S. and van den Brink, A. Decision making in response and relief phases, in: PJM van Oosterom, S Zlatanova \& EM Fendel (Eds.), Geo-information for disaster management - late papers, pp. 47-54.

Branco, P., Escalada, C. and Santos, R., 2005. Real-time 3D environment simulation applied to the disaster management field: our experience, in: PJM van 
Oosterom, S Zlatanova \& EM Fendel (Eds.), Geo-information for disaster management, Springer Verlag, Heidelberg, pp. 425-441.

Cattenstart F. J. and Scholten, H. J. 1999, Towards OpenGIS Systems, The Vector Data Storage Component Evaluated, In: Interoperating Geographic Information Systems, A. Bekovski, K.Brassel \& H. Schek (eds), Springer Verlag, Berlin, pp 163-176.

Capelleveen, E. van, 2005, Information management boost command \& control, in: P.J.M. van Oosterom, S. Zlatanova \& E.M. Fendel (Eds.), Geo-information for disaster management, Springer Verlag, Heidelberg, pp. 979-995.

Diehl, S. and van der Heide, J. 2005, Geo Information Breaks through Sector Think, in: P.J.M. van Oosterom, S. Zlatanova \& E.M. Fendel (Eds.), Geoinformation for disaster management, Springer Verlag, Heidelberg, pp. 85108.

Fabri, K. and Weets, G. 2005, ICT for Environmental Risk Management in the EU Research Context, in: P.J.M. van Oosterom, S. Zlatanova \& E.M. Fendel (Eds.), Geo-information for disaster management, Springer Verlag, Heidelberg pp. 51-56.

Kevany, M. 2005, Geo-information for disaster management: lessons from 9/11, in: P.J.M. van Oosterom, S. Zlatanova \& E.M. Fendel (Eds.), Geo-information for disaster management, Springer Verlag, Heidelberg, pp. 443-464.

Kolbe, T., Gröger, G. and Plümer, L. 2005, CityGML: Interoperable access to 3D city models, in: P.J.M. van Oosterom, S. Zlatanova \& E.M. Fendel (Eds.), Geo-information for disaster management, Springer Verlag, Heidelberg, pp. 883-899.

Kwan, M-P. and J. Lee, 2005. Emergency response after 9/11: the potential of real-time 3D GIS for quick emergency response in micro-spatial environments. Computers, Environment and Urban Systems, 29: 93-113.

Laurini, R., Servigne, S., and Noel, G. 2005, Soft Real-Time GIS for disaster monitoring, in: P.J.M. van Oosterom, S. Zlatanova \& E.M. Fendel (Eds.), Geo-information for disaster management, Springer Verlag, Heidelberg, pp. 445-479.

Meijers, M., Zlatanova, S. and Preifer, N. 2005, 3D geoinformation indoors: structuring for evacuation, in: Proceedings of Next generation 3D city models, 2122 June, Bonn, Germany, 6 p.

National Research Council, 2007. Successful Response Starts with a Map: Improving Geospatial Support for Disaster Management. Committee on Planning for Catastrophe: A Blueprint for Improving Geospatial Data, Tools, and Infrastructure, 198 pp. National Academies Press

Neuvel, J., van Borkulo, E., Scholten, H. J., Zlatanova, S., Beugelink, G. and van den Brink, A. 2006, De geografische dimensies van risicomanagement, Definitiestudierapport, Bsik project, $71 \mathrm{p}$.

Oosterom, P. van, Stoter, J., Quak, W. and Zlatanova, S. 2002, The balance between geometry and topology, , in: Advances in Spatial Data Handling, 10th International Symposium on Spatial Data Handling, D. Richardson and P. van Oosterom (Eds.), Springer-Verlag, Berlin, pp. 209-224. 
Ospina, M., 2006, What did GIS programs learn from Katrina? In Proceedings of 25th Urban Data Management Symposium, 15-17 May, Aalborg, Denmark, 6.29-6.38

$\mathrm{Pu}, \mathrm{S}$. and Zlatanova, S. 2005, Evacuation route calculation of inner buildings, in: P.J.M. van Oosterom, S. Zlatanova \& E.M. Fendel (Eds.), Geo-information for disaster management, Springer Verlag, Heidelberg, pp. 1143-1161.

Romao, T. I., Dias, A. E., Camara, A. S., Buurman, J. and Scholten, H. J. 2000, Decision Support Tools for Coastal Zone Management: Providing Decision Makers with Useful Information Through Multidimensional Visualisation Techniques', in: International Journal of Development Planning Literature, Vol. 15, No. 1, January-March, 2000, pp. 33-40.

Scholten, H.J., LoCashio, A.J. and Overduin, T. 1999, Towards a spatial information infrastructure for flood management in The Netherlands, In: Special features in coastal conservation 3, eds J. Visser \& R. Misdorp, Opulus Press, Uppsala, pp 151-160.

Scotta, A., Pleizier, I. and Scholten, H. 2006, Tangible user interfaces in order to improve collaborative interactions and decision-making, in Proceedings of 25th Urban Data Management Symposium, 15-17 May, Aalborg, Denmark, pp. 9.27-9.39

Verbree, E., Zlatanova, S. and Smit, K. 2004, Interactive navigation services through value-added navigation CycloMedia panoramic images, in: Proceedings of Sixth International Conference on Electronic Commerce, 25-27 October, Delft, The Netherlands, CDROM, $10 \mathrm{p}$

Winter, S., Iglesias, G., Zlatanova, S. and Kuhn, W. GI for the public: the terrorist attack in London, Geoinformatics Magazine, No. 7, Oct/Nov 2005, Vol. 8., pp. 18-21.

$\mathrm{Xu}, \mathrm{W}$. and Zlatanova, S., Ontologies for Disaster Management Response, In: J. Li, S. Zlatanova and A. Fabbri (Eds.); Geomatics Solutions for Disaster Management, Heidelberg, pp. 185-200

Zlatanova, S., 2005, Crisis designs, Geospatial Today, May-June 2005, Vol 4, Issues 1 , pp. 30-36.

Zlatanova, S. and Holweg, D. 2004, 3D Geo-information in emergency response: a framework, in: Proceedings of the Fourth International Symposium on Mobile Mapping Technology (MMT'2004), March 29-31, Kunming, China 6 p

Zlatanova, S., Fabbri, A., Li, J. Geo-information for Disaster Management: Large scale 3D data needed by Urban Areas, GIM International, March 2005, Volume 19, Issue 3, pp. 10-13.

Zlatanova, S. and J. Stoter, 2006, The role of DBMS in the new generation GIS architecture, Chapter 8 in S. Rana \& J. Sharma (Eds.) Frontiers of Geographic Information Technology, Springer, pp. 155-180. 